\title{
Executive functions in late childhood: age differences among
}

\section{groups}

\author{
Janice R. Pureza, Hosana A. Gonçalves, Laura Branco, Rodrigo Grassi-Oliveira, and Rochele \\ Paz Fonseca \\ Pontifícia Universidade Católica do Rio Grande do Sul, Porto Alegre, RS, Brazil
}

\begin{abstract}
Executive functions (EF) have been a major focus of interest in neuropsychology. However, there are few studies about their development in healthy children. To fill this gap in the literature, the current study aims to compare the performance in EF tasks in children from 6 to 12 ( $\mathrm{n}=90)$ years old. Three age groups (6-7, 8-10 and 11-12 yearsold) were assessed using the following instruments: verbal fluency, narrative discourse, random number generation, N-Back, Bells Test and Hayling Test. Analyses of variance were used to compare the scores among groups. There was a significant effect of age in all executive performance scores, especially between the youngest and oldest groups. The most significant differences were observed in the central executive component of working memory and inhibition, which showed a marked development between 6-7 and 8-10 years of age. In addition, a remarkable peak was observed in the tasks that assess planning and processing speed in the group of 11-12 year-old children. The current results suggest that the development of all components of EF should be further investigated in school-aged children in normative studies so that possible dissociations in the development of these abilities can be better understood. Keywords: child neuropsychological assessment, development, age, executive functions.
\end{abstract}

Received 7 September 2012; received in revised form 1 April 2013; accepted 13 May 2013. Available online 27 June 2013.

\section{Introduction}

The present study sought to investigate the development of executive functions (EF) in childhood. Executive functions can be defined as a complex group of cognitive processes of control and integration involved in the implementation of goal-directed behavior (Chan, Shum, Toulopoulou, \& Chen, 2008). These functions rely on other cognitive components such as attention, planning, the initiation and inhibition of processes and information, cognitive flexibility, and the monitoring of multiple tasks and actions (Chan et al., 2008; Dixon, Zelazo, \& De Rosa, 2010). Because of their complexity, multidimensionality, and high level of interaction with other cognitive functions, EF have been the focus of researchers in neuropsychology (Cunninghan \& Zelazo, 2007; Houdé, Rossi, Lubin, \& Joliot, 2010; Kluwe-Schiavon, Viola, \& Grassi-

Janice R. Pureza, Hosana A. Gonçalves, Laura Branco, Rodrigo Grassi-Oliveira, and Rochele Paz Fonseca, Programa de PósGraduação em Psicologia, Área de Concentração Cognição Humana, Faculdade de Psicologia, Pontifícia Universidade Católica do Rio Grande do Sul, Brasil. Correspondence regarding this article should be directed to: Janice R. Pureza, Grupo Neuropsicologia Clínica e Experimental, Prédio 11, $9^{\circ}$ andar, sala 932, Programa de Pós-Graduação em Psicologia, Faculdade de Psicologia, Pontifícia Universidade Católica do Rio Grande do Sul, Porto Alegre, CEP 90619-900, Brasil. E-mail: janicepureza@gmail.com
Oliveira, 2012; Willcutt, Doyle, Nigg, Faraone, \& Pennington, 2005).

Less attention has been paid, however, to the development of EF in children. Although it has been investigated in populations who present neurological disorders such as stroke (Anderson et al., 2010), epilepsy (Völkl-Kernstock, Bauch-Prater, Ponocny-Seliger, \& Feucht, 2009), and traumatic brain injury (Catroppa \& Anderson, 2006), and psychiatric disorders such as autism (Bishop \& Norbury, 2005; Griffith, Pennington, Wehner, \& Rogers, 1999; Russo, Flanagan, Iarocci, Berringer, Zelazo, \& Burack, 2007) and attention deficit/ hyperactivity disorder (ADHD) (Johnstone, Barry, Markovska, Dimoska, \& Clark, 2009), the development of EF has been less extensively explored in healthy children. The fact that few studies have been conducted in this population is particularly concerning given the abundance of studies in clinical populations.

Although the majority of studies of EF in children have been conducted in clinical samples, some studies have investigated healthy childhood. Some research, for example, has focused on preschool children (Blair, Zelazo, \& Greenberg, 2005; Carlson, \& Wang, 2007; Garcia-Molina, Enseñat-Cantallops, Tirapu-Ustárroz, \& Roig-Rovira, 2009; Kesek, Cunningham, Packer, \& Zelazo, 2011; Liebermann, Giesbrecht, \& Müller, 2007; Müller, Dick, Gela, Overton, \& Zelazo, 2006) and healthy children and teenagers between 7 and 16 years of age 
(Anderson, Anderson, Northam, Jacobs, \& Catroppa, 2001 Betts, Mackay, Maruff, \& Anderson, 2006; Crone, Donohue, Honomichl, Wendelken, \& Bunge, 2006; Lamm, Zelazo, \& Lewis, 2006; Muscara, Catroppa, \& Anderson, 2008). However, these studies have been largely conducted with European and North American samples, and the number of studies conducted in Latin America is quite small by comparison (Fillipetti, 2011; Fillipetti \& Minzi, 2010; Ghiglione, Fillipetti, Manucci, \& Apaz, 2011; Lipina, Martelli, Vuelta, Injoque-Ricle, $\&$ Colombo, 2004).

With regard to studies with Brazilian children specifically, the neuropsychological profile of EF in this population has not been sufficiently explored. However, recent scientific investigations have made some progress on this front. Studies of general cognitive functions in Brazilian children have been conducted and either included EF assessment (Argolo et al., 2009; Capovilla, 2006; Salles, Fonseca, Cruz-Rodrigues, Mello, Barbosa, \& Miranda, 2011) or focused specifically on EF processing in children (Pureza, Jacobsen, Oliveira, \& Fonseca, 2011; Siqueira, Scherer, Reppold, \& Fonseca, 2010).

Although the number of studies of the role of age in the development of EF is growing, their findings diverge with regard to the phase at which substantial peaks occur in the development of executive components. This might be partially explained by the high complexity of this theoretical construct and the ensuing difficulties with its definition and measurement (Hughes \& Graham, 2008; Huizinga, Dolan, \& van der Molen, 2006). Furthermore, most studies appear to have examined the development of one specific component (Anderson et al., 2010; Kerr \& Zelazo, 2004; Martin-Gonzalez et al., 2008; Matute, Chamorro, Inozemtseva, Barrios, Rosselli, \& Ardila, 2008; Thibaut, French, \& Vezneva, 2010) with very few that have investigated more than one executive process (Davidson, Amso, Anderson, \& Diamond, 2006; Martin-Gonzalez et al., 2008; Matute et al., 2008). Such variations in methodology make comparisons of the development of different executive components and identification of the associations and dissociations between them particularly difficult.

Most evidence of the relationship between age and development of $\mathrm{EF}$ has been obtained from either neurobiological or cognitive investigations or a combination of both. Neurobiological studies highlight the importance of the prefrontal lobes and their connection to other regions of the brain, especially in children between 7 and 12 years of age (Diamond, 2006; Garcia-Molina et al., 2009). These findings suggest that the maturation of frontal regions, especially the frontal cortex, is directly related to the development of EF. The brunt of this development occurs during childhood and adolescence and is closely associated with the neurobiological changes that occur during this period such as the emergence and myelination of neural pathways in the frontal lobes and an increase in synaptic density in these structures. The connections between the frontal areas and other brain regions such as the parietal, occipital, and temporal cortices, and subcortical areas such as the thalamus, are responsible for the integration of information and regulation of emotions, thoughts, and actions (Johnson, 2000; Johnson, Rossmann, \& Cohen Kadosh; 2009, Lamm et al., 2006; Matute et al., 2008). In fact, deficits in executive components such as verbal fluency, inhibitory control, and organization and planning abilities (Levin, Song, Ewing-Cobs, Chapman, \& Mendelsohn, 2001; Matute et al., 2008) have been shown to be related to alterations in maturational processes and changes or lesions in frontal regions.

Cognitive research has also made important contributions to the investigation of $\mathrm{EF}$ development, mainly through studies based on information processing and psychological and cognitive neuropsychological theories (Chan et al., 2008; Marcovitch \& Zelazo, 2009). Some such studies suggest that, during the first 5 years of childhood, observing the partial development of executive components is possible, such as the central executive of working memory, inhibition, and cognitive flexibility (Davidson et al., 2006; Garcia-Molina et al., 2009). However, this evolution appears to be progressive and asymmetrical. Whereas some cognitive components appear to be fully developed by the end of late childhood, such as the central executive of working memory and inhibition, planning and organization abilities tend to mature at later ages. Previous studies of these abilities suggest that age plays an important role in the development of these processes (Matute et al., 2008), reinforcing the idea that EF do not develop entirely until adulthood (Diamond, 2006; Dibbets \& Jolles, 2006; Hughes, \& Graham, 2008; Huizinga et al., 2006; Klenberg, Korkman, \& Lahti-Nuuttila, 2001; Marcovich \& Zelazo, 2009).

Lastly, some important information has been obtained from studies interested in both neurobiological and cognitive data. The merging of these two lines of neuropsychological investigation allows the development of comprehensive theories regarding the structural and functional aspects of human cognitive development (Buchweitz, Mason, Tomitch, \& Just, 2009; Cunningham \& Zelazo, 2007; Ellison \& Semrud-Clikeman, 2007). Such studies have relied on neuroimaging techniques to better comprehend the role of neurobiological vs. cognitive variables in EF development. Neuroimaging studies point to the participation of the parietal, occipital, and temporal cortices in tasks previously thought to require mostly frontal lobe involvement. These patterns of activation do not necessarily occur in children in the same manner as in adults. In fact, some studies found activation in different areas that depended on the child's stage of development (García-Molina et al., 2009; Soltész, Goswami, White, \& Szücs, 2010; Tamnes, Ostbya, Walhovda, Westlyea, Due-Tønnessenb, \& Fjell, 2010). At $\sim 6$ to 7 years of age, significant progress appears in the development of interhemispheric associative areas of the motor and sensorial cortices. At $\sim 10$ years of age, the development of prefrontal regions takes place. 
As a result of these processes, children at $\sim 10$ years of age begin to exhibit an increasingly wider repertoire of symbolic functions such as the development of abstract thought. Finally, at $\sim 14$ years of age, the development of associative brain circuitry that links frontal and limbic areas occurs (Matute et al., 2008; Miranda \& Muszkat, 2004). This stage of development is extremely important for the characterization of EF because the growth of various brain regions coincides with the development of many executive components. The development of these complex cognitive abilities depends on the maturation of frontal regions and their intercommunication with other cortical areas and structures such as the hippocampus, cerebellum, and basal ganglia (García-Molina et al., 2009; Matute et al., 2008).

In summary, the research described above indicates a degree of dissociation in the development of $\mathrm{EF}$ components, although no definitive conclusions regarding the nature of these dissociations have been made. One of the factors that might contribute to this situation is the relatively low number of studies of EF in children compared with the number of studies that involve neuropsychological assessment in adults. Additionally, a wide variety of tools has been used for the assessment of EF in children, hampering the understanding of how different executive components are processed. Therefore, further studies need to be conducted with healthy children so the development of EF can be understood with greater depth and specificity.

To contribute to the extant research on the role of age in the processing of EF components, the present study sought to determine whether significant differences in EF exist in 6- to 12-year-old children. To facilitate the analysis and interpretation of the data, the children were divided into three groups: 6-7 years old, 8-10 years old, and 11-12 years old. The main hypothesis was that 11and 12-year-old children would present higher scores in neuropsychological assessment measures than 8- to 10 -year-old and 6- to 7-year-old children. The main differences between these groups were hypothesized to be found in assessments of the central executive component of working memory, cognitive flexibility, and inhibition. The main contributions of this paper to the current scientific literature include overcoming some of the methodological difficulties identified in previous research such as the use of correlational or regression analyses (Davidson et al., 2006; Huizinga et al., 2006) in the interpretation of the data. Although widely used, this methodology may limit the characterization of age ranges in late childhood with regard to EF processing. More specific conclusions can be drawn using a comparative study design among age groups, which would generate more relevant data for clinical and educational purposes in which the age ranges used correspond to the ages of children, in particular school grades. Finally, the present study makes an important contribution in terms of its methodology by assessing EF in Brazilian children using new neuropsychological tools developed or adapted exclusively for children from this country.

\section{Methods \\ Participants}

The sample was composed of first- to sixth-graders between 6 and 12 years of age who were attending public schools in southern Brazil (Porto Alegre). All children selected for the study were capable of self-report and had no history of learning difficulties. The participants were recruited using convenience sampling.

Of the total sample, 22 children were excluded for meeting one or more of the following criteria: (a) presenting speech dysfunction, uncorrected neurological or sensorial disorders, or reporting to have repeated grades or received psychological assistance in a sociodemographic self-report questionnaire about cultural and health aspects answered by the parents or those responsible for the children $(n=14),(\mathrm{b})$ presenting a score that suggests intellectual difficulties on the Raven's Colored Progressive Matrices (Raven, Court, \& Raven, 1995; Raven, Court, \& Raven, 1998), with a cutoff score $<26^{\text {th }}$ percentile $(n=1)$, and (c) showing signs suggestive of ADHD on the Conners Abbreviated Teacher Rating Scale (Conners, 1969; Barbosa \& Gouveia, 1993), with specific cut-off scores for each age range for Brazilian children (Brito, 1987; Brito \& Pinto, 1991; $n=7$ ). Thus, the final sample comprised 90 typically developing children ( $n=53$ girls) from three different public schools and distributed into three groups according to age: Group 1 (31 children who were 6 years of age $[n=15$, nine girls] and 7 years of age $[n=16$, nine girls]); Group 2 (32 children who were 8 years of age $[n=12$, six girls], 9 years of age [ $n=10$, seven girls], and 10 years of age [ $n=10$, three girls]), and Group 3 (27 children who were 11 years of age $[n=15$, nine girls] and 12 years of age [ $n=12$, eight girls]). No significant differences in gender distribution were found between groups $\left[\chi^{2}(2)=.698, p=.705\right]$. Refer to Table 1 for data regarding the sociodemographic characteristics of the participants.

\section{Materials}

Two instruments were used as screening tools for the exclusion criteria. Raven's Colored Progressive Matrices (Raven et al., 1995, 1998) measured intellectual difficulties based on nonverbal stimuli. The outcome variable used in the analyses was the raw score adjusted to its respective percentile score calculated according to normative data. Conners Abbreviated Teacher Rating Scale (Conners, 1969; Barbosa \& Gouveia, 1993) measured signs suggestive of ADHD. Raw scores were used to classify each child's frequency and intensity of symptoms at or above cut-off scores for each age range based on normative data for Brazilian children (Brito, 1987; Brito \& Pinto, 1991).

The remaining instruments in the study were used for EF assessment. The unconstrained, phonemic, and semantic verbal fluency tasks of the Montreal Communication Evaluation Battery (MAC Battery) (Fonseca, Parente, Côté, Ska, \& Joanette, 2008), children's version, were used to assess planning, verbal initiation and inhibition, lexical memory, working memory, and cognitive flexibility. In the 
Table 1. Sociodemographic characterization of the three age groups

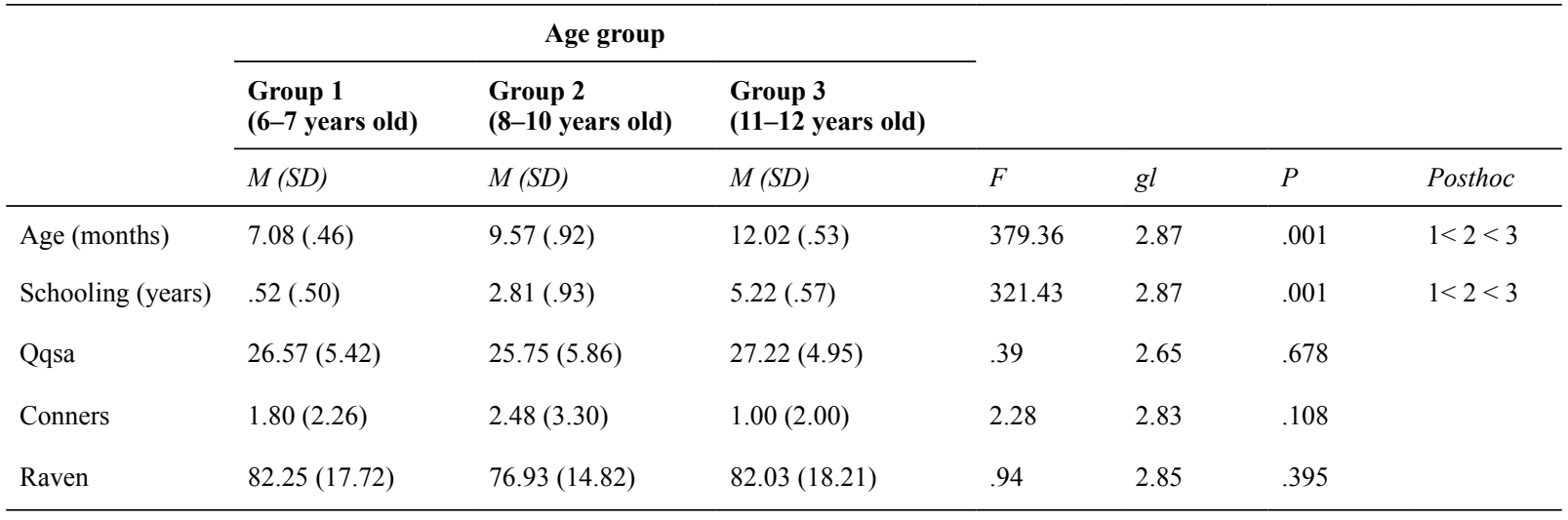

$M$, average; $S D$, standard deviation; Qqsa, Questionnaire on Health and Sociocultural Aspects.

unconstrained modality, the children were instructed to say all of the words they could remember-with the exception of proper names and numbers - for $2.5 \mathrm{~min}$. For phonemic fluency, the children were asked to say as many words that begin with the letter "p" as they could for 2 min. Finally, for semantic fluency, the children were required to say words related to clothing for $2 \mathrm{~min}$. Only correct answers were scored, excluding perseverations (repeated words) and invalid words (outside the established criteria for each type and neologisms).

Random number generation (RNG) adapted from the original task by Towse and Neil (1998) and Towse and McLachlan (1999) was used to assess executive components of inhibition, cognitive flexibility, and selfmonitoring. For this task, the children were asked to verbalize a number from 1 to 10 in a random fashion every time they heard a sound stimulus that was prerecorded on audio equipment. In the first $90 \mathrm{~s}$ of the task, the children were instructed to say numbers at 2 -s intervals. In the last $90 \mathrm{~s}$ of the task, the children were instructed to say numbers at 1 -s intervals. The researcher emphasized that the children should avoid saying consecutive sequences of numbers or repeating numbers within a short period of time. Therefore, numbers that were repeated within three intervals were considered perseverations. Accurate answers were calculated according to speed (intervals). The maximum score possible was 45 for the 2-s intervals and 90 for the 1-s intervals (Towse \& McLachlan, 1999).

The Bells test for children (adapted from Gauthier, Dehaut, \& Joanette, 1989, and Vannier, Chevignard, Pradat-Diehl, Abada, \& Agostihini, 2006) assessed concentrated and selective attention, visual perception, and processing speed. The task consisted of asking the children to cancel targets (i.e., bells with handles and clappers) among some distractors (i.e., bells with no handle and no clapper and other unrelated objects) as fast as they could. The examiner monitored the order in which the targets were identified and crossed out and identified the strategy used by the child in the visual search for the bells. For this study, the time spent by each child performing the task and visual search strategy used were considered.
The Narrative Discourse Subtest of inferential processing adapted to children from the MAC Battery (Fonseca et al., 2008) was composed of three stages: $(i)$ partial retelling of a story, (ii) complete retelling of the same story, and (iii) text comprehension by giving the story a title and answering 12 comprehension questions. Throughout these stages, the examiner observed whether the child was able to infer the moral of the story. For this study, the goal was to examine executive components, and only the occurrence of inferential processing or lack thereof was analyzed.

The N-Back task (adapted from Dobbs \& Rule, 1989) examined the central executive component of working memory. In the present study, auditory and visual N-Back versions were used. In the visual N-Back version (Lima et al., 2011), the children were shown a sequence of photographs of animals and asked to say their names. However, instead of naming the animal whose picture they were currently seeing, they should name the last $(n=1)$, second-to-last $(n=2)$, or thirdto-last $(n=3)$ animal picture they were shown. In the auditory N-Back task (De Nardi, Prando, Vieira, Stein, Fonseca \& Grassi-Oliveira, 2013), the children listened to a sequence of numbers presented at 1-s intervals. The children were first asked to repeat every number. Similar to the visual N-Back task, they were then asked to repeat the last, second-to-last, or third-to-last number presented (conditions $n=1, n=2$, and $n=3$ ). In this study the span score (i.e., the total of correct answers until the first error) of a sequence of 10 numbers for each level of complexity was calculated.

The Hayling test (Burgess \& Shallice, 1997), adapted to the Brazilian population by Fonseca, Oliveira, Gindri, Zimmermann, and Rappold (2010) and Siqueira, Scherer, Rappold, \& Fonseca (2010) analyzed the executive components of verbal initiation and inhibition. The test involved 30 sentences divided into two sections with 15 sentences each. During the first section, the children were asked to complete each sentence as fast as they could with a word that was syntactically and semantically consistent with the sentence's context. In the second section, the children were instructed to complete the sentences as quickly as possible, but they were instead instructed to 
use words that were unrelated to the sentence's context. The variables analyzed in this task were the total answer latencies for each section and number of errors for 15 sentences in part A and 15 sentences in part B. Each error in Part B was also qualitatively analyzed and received a score of 1 to 3 . A complementary score was also calculated by subtracting the total answer latencies in section A from the total answer latencies in section B. This score measured the difference in processing speed between tasks that rely mostly on inhibition (part B) or initiation (part A).

The tasks described here can be grouped according to the executive components they assess. To assess organization and planning, clinicians can consider the children's performance in the narrative discourse task and cancellation strategy in the Bells test. Inhibition and initiation components can be examined using verbal fluency tasks, the RNG task and Hayling test (as a bipartite test, part A mainly evaluates verbal initiation, and part B mainly evaluates inhibition). To estimate working memory processing, more specifically the central executive component, partial and full narrative discourse retelling scores and N-Back scores can be analyzed together. Finally, when assessing processing speed, the time variables recorded in the Bells test, RNG task, and Hayling test are essential.

Importantly, all of the unpublished tests used in the present study are under development by research groups who have collected sufficient evidence of the tests' reliability, content validity, and criterion validity. Some of this evidence was obtained using correlational studies of test performance scores in children from 6 to 12 years of age (Pureza et al., 2011).

\section{Procedures}

The present study was approved by the Ethics Committee in Research of Pontifícia Universidade Católica do Rio Grande do Sul (no.09/04864). Participation in the study was voluntary and anonymous, and written and informed consent was obtained from the parents of the children. The children were assessed individually in their own schools in a quiet, well-lit, and well-ventilated environment in two sessions of $\sim 1 \mathrm{~h}$ each. In the first session they were screened for inclusion criteria and responded to instruments related to sample characterization. In the second session, neuropsychological tests were administered in two different orders, both selected a priori to control for order effects and possible interference among similar subtests.

\section{Statistical analysis}

The Statistical Package for the Social Sciences (SPSS) v.15.0 was used for the analysis. The KolmogorovSmirnov test confirmed that the data had a normal distribution. Thus, the task scores were compared among groups using one-way analysis of variance (ANOVA) with age group as a factor followed by the Bonferroni post $h o c$ tests. The distribution of categorical variables in each age group such as gender, interference processing in the Narrative Discourse task, and cancellation strategies in the Bells test was assessed using the $\chi^{2}$ test. Significance was considered at $\alpha=0.05$.

\section{Results}

The descriptive and comparative EF score data are presented in Tables 2 and 3 with post hoc results displayed in the last column.

Table 2 shows significant differences in scores among age groups. All three groups differed in the phonemic and semantic fluency tasks and accuracy in part A of the Hayling test. In the other scores, differences were found only between two of the groups.

The group of older children had better performance in the RNG task and required less time to complete the Bells test and Hayling test. They also had better performance in the unconstrained verbal task. Table 3 shows span variable performance in the visual and auditory N-Back tasks.

Table 3 shows that all measures of the central executive component of working memory were influenced by age, showing converging results in the visual and auditory forms of the N-Back tasks. The oldest group outperformed the other two groups in both the visual and auditory 2-back and 3-back tasks, and the youngest children performed at a significantly poorer level than the other two groups across all three complexity levels of the task. The performance of the intermediate age group exhibited an interesting trend because it was similar to the older children in the easiest version of the task (1-back) but closer to the younger children in the most difficult version (3-back). In both the auditory and visual 2-back tasks, all three group scores were significantly different from each other. With regard to the analysis of the categorical variables in the study, Figure 1 displays the distribution of the three age groups in terms of the percentage of children in each group who were able to successfully engage in inferential processing during narrative discourse and use organized canceling strategies in the Bells test.

The data shown in Figure 1 demonstrate the evolution of the age groups' performance with regard to the inferential processing component of the narrative discourse tasks. The groups significantly diverged in their ability to make this inference $\left[\chi^{2}(2)=18.927, p<.001\right]$. The majority of children in the 11- to 12-year-old age group were able to process this inference, but only $40-50 \%$ of the children in the 6-to 7-year-old and 8-to 10-year-old groups were able to trigger such complex processing.

The strategies used by the age groups (Figure 1b) indicate that younger children were more likely to use disorganized visual search strategies to locate the target stimuli in the visual canceling paradigm presented. Grouping organized and disorganized strategies and comparing the percentage of children in each group who used each type of strategy revealed contrasts among groups $\left[\chi^{2}(2)=4.794, p=.029\right]$. 
Table 2. Performance on the RNG task, verbal fluency task, Hayling test, and Bells test in the three age groups.

\begin{tabular}{|c|c|c|c|c|c|c|c|c|}
\hline & & \multicolumn{3}{|c|}{ Age group } & & & & \\
\hline & & $\begin{array}{l}\text { Group } 1 \\
\text { (6-7 years old) }\end{array}$ & $\begin{array}{l}\text { Group } 2 \\
\text { (8-10 years old) }\end{array}$ & $\begin{array}{l}\text { Group } 3 \\
\text { (11-12 years old) }\end{array}$ & & & & \\
\hline$M(S D)$ & & $M(S D)$ & $M(S D)$ & $M(S D)$ & $F$ & $g l$ & $p$ & Post hoc \\
\hline \multirow{2}{*}{ RNG } & $2 \mathrm{~s}$ & $29.90(7.29)$ & $35.94(5.16)$ & 38.77 (4.47) & 17.55 & 2.86 & $<.001$ & $1<2,1<3$ \\
\hline & $1 \mathrm{~s}$ & $43.58(16.05)$ & $52.59(12.67)$ & $60.73(11.80)$ & 11.11 & 2.86 & $<.001$ & $1<2,1<3$ \\
\hline \multirow{3}{*}{ VF } & Free & $24.68(14.63)$ & $34.56(15.84)$ & $56.30(21.59)$ & 24.62 & 2.87 & $<.001$ & $1<3,2<3$ \\
\hline & Phonemic & $8.87(4.73)$ & $12.50(4.98)$ & $16.70(6.45)$ & 15.24 & 2.87 & $<.001$ & $1<2,1<3,2<3$ \\
\hline & Semantic & $10.59(3.38)$ & $15.16(3.64)$ & $19.74(5.13)$ & 35.12 & 2.85 & $<.001$ & $1<2,1<3,2<3$ \\
\hline \multirow{5}{*}{ Hayling test } & Time A & $40.94(18.44)$ & $41.01(28.22)$ & $25.13(19.55)$ & 4.45 & 2.81 & .015 & $1>3,2>3$ \\
\hline & Errors A & $2.37(1.30)$ & $1.06(.94)$ & $.22(.42)$ & 34.23 & 2.83 & $<.001$ & $1>2,1>3,2>3$ \\
\hline & Time B & $69.57(22.66)$ & $72.75(32.27)$ & $45.18(25.07)$ & 7.37 & 2.83 & $<.001$ & $1>3,2>3$ \\
\hline & Errors/15 B & $6.44(4.08)$ & $8.31(3.40)$ & $4.78(2.77)$ & 7.68 & 2.83 & $<.001$ & $2>3$ \\
\hline & Errors/45 B & $16.30(11.54)$ & $20.44(9.71)$ & 11.89 (7.62) & 5.62 & 2.83 & .005 & $2>3$ \\
\hline Bells test & Time & $161.57(73.23)$ & $125.31(6.64)$ & $99.09(1.06)$ & 10.7 & 2.86 & $<.001$ & $1>2,1>3$ \\
\hline
\end{tabular}

RNG, random number generation; VF, verbal fluency.

Table 3. Auditory and visual N-Back task performance in the three age groups

\begin{tabular}{|c|c|c|c|c|c|c|c|c|}
\hline & & \multicolumn{3}{|c|}{ Age group } & & & & \\
\hline & & $\begin{array}{l}\text { Group } 1 \\
\text { (6-7 years old) }\end{array}$ & $\begin{array}{l}\text { Group } 2 \\
\text { (8-10 years old) }\end{array}$ & $\begin{array}{l}\text { Group } 3 \\
\text { (11-12 years old) }\end{array}$ & & & & \\
\hline & & $M(S D)$ & $M(S D)$ & $M(S D)$ & $F$ & $g l$ & $P$ & Post hoc \\
\hline \multirow{3}{*}{$\begin{array}{l}\text { Visual } \\
\text { N-Back }\end{array}$} & 1- Span & $5.17(3.10)$ & $8.38(2.64)$ & $9.41(1.55)$ & 21.88 & 2.86 & $<.001$ & $1<2,1<3$ \\
\hline & 2-Span & $1.37(2.07)$ & $3.13(2.48)$ & $5.96(3.19)$ & 22.46 & 2.86 & $<.001$ & $1<2,1<3,2<3$ \\
\hline & 3-Span & $.10(.54)$ & $1.53(2.71)$ & $4.00(3.34)$ & 17.93 & 2.86 & $<.001$ & $1<3,2<3$ \\
\hline \multirow{3}{*}{$\begin{array}{l}\text { Auditory } \\
\text { N-Back }\end{array}$} & 1-Span & $5.00(3.06)$ & $8.22(8.79)$ & $8.74(2.03)$ & 16.74 & 2.86 & $<.001$ & $1<2,1<3$ \\
\hline & 2- Span & $1.13(2.14)$ & $3.00(2.15)$ & $5.30(2.89)$ & 21.40 & 2.86 & $<.001$ & $1<2,1<3,2<3$ \\
\hline & 3- Span & $.37(1.18)$ & $1.31(2.30)$ & $3.96(3.00)$ & 19.07 & 2.86 & $<.001$ & $1<3,2<3$ \\
\hline
\end{tabular}

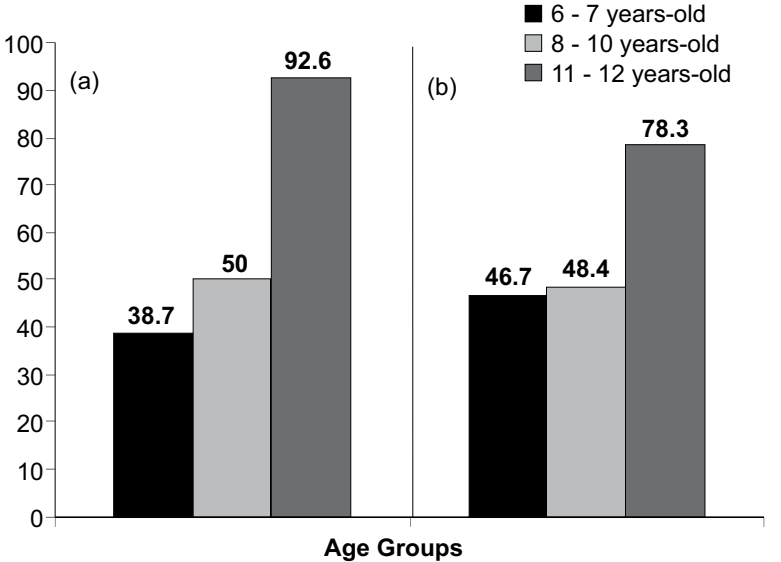

Figure 1. Percentage of participants in each group who successfully (a) engaged in inferential processing during the Narrative Discourse task and (b) used organized cancellation strategies in the Bells test.

\section{Discussion}

The present study sought to verify the relationship between age and EF processing in late childhood. Age appeared to be closely linked with EF development in this sample. Differences among all three age groups were observed in some of the neuropsychological tasks. These results support the extant literature, highlighting the influence of this biological and demographic factor on EF performance (Brocki \& Bohlin, 2004; Davidson et al., 2006; Matute et al., 2008). Significant differences were found among all three groups in the phonemic verbal fluency task (Group $1<$ Group 2, Group $1<$ Group 3 , Group $2<$ Group 3), semantic verbal fluency task (Group $1<$ Group 2, Group $1<$ Group 3, Group $2<$ Group 3 ) and accuracy in part A of the Hayling test (Group 1>Group 2, Group 1>Group 3, Group 2>Group 3). 
Scores in the other executive tasks differed significantly between at least two age groups.

The existing literature in regard to the role of age in the development of EF in healthy children is scarce and controversial with regard to the ages at which peaks of executive development occur. Davidson et al. (2006), Garcia-Molina et al. (2009), Huizinga et al. (2006), and Marcovich and Zelazo (2009) reported different paths in the development of some components of EF based on age, focusing mostly on the central executive component of working memory, cognitive flexibility, and inhibition. These studies generally support the hypothesis that major developments in executive processing occur between the beginning and end of late childhood.

The children's performance in specific tasks shows significant differences in RNG performance between the youngest group and the other two age groups. The fact that the performance of 8- to 10-year-olds did not differ from 11- to 12 -year-olds may suggest that 8 -year-old children already possess partially developed self-monitoring and inhibitory control abilities that remain stable until 11-12 years of age. This pattern of age differences in performance in the RNG task could be observed in both the 1-s and 2-s interval modalities even when numbers are elicited at 1-s intervals and the children must have faster answering strategies, thus making the task considerably more difficult.

The hypothesis that differences in performance among groups may be explained by increasing age was investigated by Towse and MacLachlan (1999). They used a correlational study in which 42 schoolage children (8-11 years old) were assessed with a neuropsychological battery that included the RNG task. The authors examined the relationships between children's development (i.e., age), time to complete executive tasks, and accuracy in the task. The authors found correlations between age and the examined variables, especially the time required to complete the tasks. These findings support the present results, suggesting that younger children ( $\sim 6$ years old) appear to have more difficulties in tasks in which the demand of the central executive of working memory is greater.

Further evidence regarding EF development can be garnered from the results of the verbal fluency tasks. Differences were found between the 6- to 7-year-old and 8- to 10-year- old groups in the unconstrained verbal fluency modality. Differences among all three age groups were found in the phonemic and semantic verbal fluency tasks. One possible explanation for these findings is that the latter modalities involve searching based on criteria for lexical appropriateness, which demands more inhibitory control. As such, these tasks may be more discriminating in terms of age than the unconstrained fluency modality, revealing peaks of development through late childhood. Furthermore, semantic verbal fluency has been strongly associated with EF (Klenberg et al., 2010; Nieto, Galtier, Barroso, \& Espinosa, 2008), especially as it relates to cognitive flexibility and the search strategies for words produced in the task. With regard to the phonemic verbal fluency based on phonological-orthographical search criteria, studies suggest that phonological development in children begins early, and their phonetic sensitivity is heightened when they begin to learn to read. Therefore, they make initial connections between the written form and pronunciation of words with greater ease (Laing \& Hulme, 1999). Younger children have more rudimentary connections between oral and written language, which are both fundamental to the development of lexicalphonological and lexical-semantic search strategies.

Further differences in the performance of the three age groups were found in the time required to complete both parts of the Hayling test. The 11- and 12-yearold children were significantly faster than the younger children, suggesting later evolution of the verbal processing speed component during childhood. This hypothesis was corroborated by McAuley and White (2010) who investigated the relationships between age and processing speed, inhibition, and working memory. These authors observed a tendency toward increased processing speed as children grew older.

Interesting findings were also obtained from the accuracy scores in the Hayling test. The present results revealed differences in accuracy in both parts of the test only between the two older age groups, with 8- to 10-year- old children making more mistakes than 11to 12-year-old children. The differences observed in Part B may be attributable to a peak in the evolution of the verbal inhibition component at $\sim 11-12$ years of age. This portion of the task demands the use of inhibitory control, requiring respondents to avoid answers that are semantically related to the sentences. No differences in performance were found between the 6- to 7-year-old and 11- to 12-year-old groups in Part B. One possible explanation for this result is that children at 6 and 7 years of age can find answers that are not semantically related to a sentence with greater ease because syntactic-semantic knowledge is still in the beginning stages of development and does not interfere with attempts to complete sentences with unrelated words. The opposite process can be observed in older children whose linguistic and inhibitory components are more developed. The performance of 8- to 10-year-old children represents a middle ground in development in which syntactic-semantic knowledge is already able to quickly provide answers that accurately complete the sentences, but inhibitory control is not yet sufficiently able to prevent these answers when an unrelated word should be produced.

Differences were found between the 6- to 7-yearold and 11- to 12-year-old-groups in the time taken to complete the Bells test. This result suggests that the processing speed of visual stimuli may reach a developmental peak in children at $\sim 8$ years of age. This hypothesis is reinforced by studies that found that the time necessary to complete other neuropsychological tasks that demand motor responses decreases as children get older (Barral, Debû, \& Rival, 2006; Matute et al., 
2008). These results illustrate the intricate relationships between EF and other cognitive features. Executive function tests often tap into multiple constructs, and underlying abilities such as processing speed can greatly influence executive performance.

Notably, the developmental peak observed occurred at 8 years of age in this task, but it could have occurred at a later age if the task was more complex and still measured similar cognitive abilities. Thus, the ages that may mark developmental peaks should be considered approximations because the peaks themselves may vary depending on task difficulty.

With regard to the qualitative variable of the visual search strategy in the Bells test, younger children noticeably made use of less organized strategies when searching for the targets. This may be related to the fact that planning and organizational abilities do not reach a developmental peak until the ages of 11 and 12 (Matute et al., 2008).

Another interesting observation from the present study was the trajectory of performance in the visual and auditory N-Back tasks. In the N-Back 1 task, meaningful differences were observed between the youngest age group and other children. The 8- to 10-year-old and 11- to 12-year-old groups, however, did not differ from each other, corroborating studies that suggested that the central executive component of working memory is sufficiently developed by the beginning of late childhood to successfully complete cognitive tasks where facilitation is available (Diamond, 2006). In the N-Back 2 task, significant differences were found among all three age groups. This result indicates that the groups may be at distinct stages in the continuum of central executive development because they differed in their ability to complete a task with increased demands placed on this component of working memory. Nonetheless, in the N-Back 3 task, the 11- to 12-year-old children exhibited significantly different performance from the other two groups which, in turn, did not differ from each other. This task was particularly difficult for the younger children. Twenty-eight children between the ages of 6 and 7 and 22 children between the ages of 8 and 10 obtained scores of " 0 " in the N-Back 3 task. These data suggest that the central executive is sufficiently developed to deal with this level of complexity and cognitive demand only at a later age. This hypothesis is supported by Vuontonela et al. (2003). They studied typically developing children in which 9- and 10-yearolds presented superior development to 6- and 8-yearolds in terms of accuracy in the N-Back tasks. These findings support the hypothesis that both the central executive component of working memory and capacity for inhibitory control begin their developmental trajectory before the end of late childhood and progress until reaching a peak at $\sim 11-12$ years of age.

The analyses of the occurrence of inferential processing during the narrative discourse task allowed the identification of a gradual evolution of the children's inferential capacity, which appears to be almost entirely developed by 11-12 years of age. Performance in the different age groups in the present study suggests that younger children may have had more difficulty drawing inferences about the presented narrative because such processing requires planning and organizational abilities and other cognitive strategies that tend to develop at later ages. These observations are supported by other studies that drew parallels between the capacities of inferential processing and text comprehension and the development of EF during childhood. Cutting, Matterek, Cole, Levine, and Mahone (2009) investigated the relationship between verbal memory, planning and organizational abilities, and text comprehension in 9- to 14-year-old children, reinforcing the idea that executive abilities are important for children's performance in verbal comprehension tasks that involve working memory, planning, organization, and information monitoring.

\section{Conclusions}

The present results suggest that age significantly influences children's performance in a series of EF tasks. These findings are consistent with previous studies in which the greatest developmental differences were found between 6- to 7-year-old and 11- to 12-yearold children. These data support the hypothesis of a progressive evolution of the development of executive processing during late childhood. Nevertheless, the development of each of these abilities may follow slightly different trajectories. The central executive component of working memory and inhibitory control appear to develop at a mostly constant pace throughout childhood, although slight differences in these components' developmental trajectories could be observed in the performance of the three age groups. The cognitive flexibility, planning ability, and processing speed results suggest that these abilities present a significant peak at $\sim 11$ and 12 years of age. These results indicate the necessity for further studies of EF in which children's performance is compared with normative data to better investigate the role of age in performance on such tasks and outline the parameters of expected performance for children of all ages who attend either public or private schools. These data may then be used to enhance or to discard clinical diagnoses.

However, a few methodological limitations of the present study should be considered. Because of the sample size and interest in obtaining an overview of childhood development based on specific age ranges, the present study involved comparative analyses. The present findings should be confirmed by further studies with larger samples so age can be analyzed as a continuous variable and studies that utilize a longitudinal design.

Studies that investigate the development of EF components in preschoolers until the end of late childhood and adolescence will also be essential to gain a better understanding of the chronological evolution of these complex cognitive processes. A detailed analysis of the relationships among different executive components 
in children's development is also fundamental for both developmental neuropsychology and clinical practice.

Knowledge of the development of EF in different age ranges through late childhood is also very important to identify dysexecutive syndromes in different neurological or psychiatric disorders in children with executive symptoms. For example, knowledge of the different trajectories of development for each $\mathrm{EF}$ component and how they are reflected by different measurement modalities may be useful for assessing EF in ADHD and autism, among others.

\section{References}

Anderson, V. A., Anderson, P., Northam, E., Jacobs, R., \& Catroppa, C. (2001). Development of executive functions through late childhood and adolescence in an Australian sample. Developmental Neuropsychology, 20(1), 385-406.

Anderson, V., Spencer-Smith, M., Coleman, L., Anderson, P., Williams, J., Greenham, M., ... Jacobs, R. (2010). Children's executive functions: Are they poorer after very earlier brain insult. Neuropsychologia, 48, 2041-2050.

Argolo, N., Bueno, O. F. A., Shaver, B., Godinho, K., Abreu, K., Duran, Lima, F., ... Seabra, A. G. (2009). Adaptação Transcultural da Bateria Nepsy: Avaliação neuropsicológica do desenvolvimento: Estudo-piloto. Avaliação Psicológica, 8(1), 59-75.

Barbosa, G. A., \& Gouveia, V. V. (1993). O fator hiperatividade do Questionário de Conners: Validação conceptual e normas diagnósticas. Temas: Teoria e Prática de Psiquiatra, 23(46), 188202.

Barral, J., Debû, B., \& Rival C. (2006). Developmental changes in unimanual and bimanual aiming movements. Developmental Neuropsychology, 29, 415-429.

Betts, J., Mackay, J., Maruff, P., \& Anderson, V. (2006). The development of sustained attention in children: The effect of age and task load. Child Neuropsychology, 12, 205-221.

Bishop, D. V. M., \& Norbury, C. F. (2005). Executive functions in children with communication impairments, in relation to autistic symptomatology: 2. Response inhibition. Autism, 9(1), 29-43.

Blair, C., Zelazo, P. D., \& Greenber, M. T. (2005). The measurement of executive functions in early childhood. Developmental Neuropsychology, 28(2), 561-571.

Brito, G. N. O. (1987). The Conners Abbreviated Teacher Rating Scale: Development of norms in Brazil. Journal of Abnormal Child Psychology, 15(4), 511-518.

Brito, G. N. O., \& Pinto, R. C. A. (1991). A composite teacher rating scale: Analysis in a sample of Brazilian children. Journal of Clinical and Experimental Neuropsychology, 13, 417-418.

Brocki, K. C., \& Bohlin, G. (2004). Executive functions in children aged 6 to 13: A dimensional and developmental study. Developmental Neuropsychology, 26, 571-593.

Buchweitz, A., Mason, R. A., Tomitch, L. M. B., \& Just, M. A. (2009). Brain activation for reading and listening comprehension: An fMRI study of modality effects and individual differences in language comprehension. Psychology \& Neuroscience, 2(2), 111-123.

Burgess, P. W., \& Shalice, T. (1997). The Hayling and Brixton tests. Bury St. Edmunds: Thames Valley Test Company.

Capovilla, A. G. S. (2006). Desenvolvimento e validação de instrumentos neuropsicológicos para avaliar funções executivas. Avaliação Psicológica, 5(2), 239-241.

Catroppa, C., \& Anderson V. (2006). Planning, problemsolving and organizational abilities in children following traumatic brain injury: Intervention techniques. Pediatric Rehabilitation, 9(2), 89-97.

Chan, R. C. K., Shum, D., Toulopoulou, T., \& Chen, E. Y. H. (2008). Assessment of executive functions: Review of instruments and identification of critical issues. Archives of Clinical Neuropsychology, 23, 201-216.

Carlson, S. M., \& Wang, T. S. (2007). Inhibitory control and emotion regulation in preschool children. Cognitive Development, 22, 489-510.

Conners, C. K. (1969). A teacher rating scale for use in drug studies with children. American Journal of Psychiatry, 126, 884-888.

Crone, E. A., Donohue, S. E., Honomichl, R., Wendelken, C., \& Bunge, S. A. (2006). Brain regions mediating flexible rule use during development. Journal of Neuroscience, 26(43), 1123911247.

Cunningham, W. A., \& Zelazo, P. D. (2007). Attitudes and evaluations: A social cognitive neuroscience perspective. Trends in Cognitive Sciences, 11, 97-104.

Cutting, L. E., Materek, A., Cole, A. A., Levine, T. M., \& Mahone, E. M. (2009). Effects of fluency, oral language, and executive function on reading comprehension performance. Annals of Dyslexia, 59(1), 34-54.

Davidson, M. C., Amso, D., Anderson, L. C., \& Diamond, A. (2006). Development of cognitive control and executive functions from 4 to 13 years: Evidence from manipulations of memory, inhibition, and task switching. Neuropsychologia, 44, 2037-2078.

De Nardi, T. C., Vieira, B. S., Prando, M. L., Stein, L. M., Fonseca, R. P., \& Grassi-Oliveira, R. (2013). Tarefa n-back auditiva: Diferença entre diferentes grupos etários. Reflexão e Crítica, 26, 1-9.

Diamond, A. (2006). The early development of executive functions. In E. Bialystok, \& F. I. M. Craik (Eds.), Lifespan cognition: Mechanisms of change (pp. 70-95). Oxford: Oxford University Press.

Dibbets, P., \& Jolles, J. (2006). The switch task for children: Measuring mental flexibility in young children. Cognitive Development, 21, 60-71.

Dixon, M. L., Zelazo, P. D., \& De Rosa, E. (2010). Evidence for intact memory-guided attention in school-aged children. Developmental Science, 13(1), 161-169.

Dobbs, A. R., \& Rule, B. G. (1989). Adult age differences in working memory. Psychology and Aging, 4, 500-503.

Ellison, P. A. T., \& Semrud-Clikeman, M. (2007). Child neuropsychology and interventions for neurodevelopmental disorders. New York: Springer.

Fillipetti, V. A. (2011). Funciones ejecutivas emninos escolarizados: Efectos de laedad y del estrato socioeconômico. Avances en Psicologia Latinoamericana, 29(1), 98-113.

Fillipetti, V. A., \& Minzi, M. C. R. (2010). Efectos de un programa de intervención para aumentar la reflexividad y la planificación en um ámbito escolar de alto riesgo por pobreza. Universitas Psichologica, 10(2), 341-354.

Fonseca, R. P., Parente, M. A. M. P., Côté, H., Ska, B., \& Joanette, Y. (2008). Bateria Montreal de Avaliação da Comunicação: Bateria $M A C$. São Paulo: Pró-Fono.

Fonseca, R. P., Oliveira, C., Gindri, G., Zimmermann, N., \& Reppold, C. (2010). Teste Hayling: Um instrumento de avaliação de componentes das funções executivas. In C. Hutz (Ed.), Avaliação psicológica e neuropsicológica de crianças e adolescentes. São Paulo: Casa do Psicólogo.

Garcia-Molina, A., Enseñat-Catallops, A., Tirapu-Ustárroz, J., \& Roig-Rovira, T. (2009). Maduración de la corteza prefrontal y desarrollo de las funciones ejecutivas durante los primeros cinco años de vida. Revista de Neurologia, 48(8), 435-440.

Gauthier, L., Dehaut, F., \& Joanette, Y. (1989). The Bells Test: A quantitative and qualitative test for visual neglect. International Journal of Clinical Neuropsychology, 11, 49-54.

Ghiglione, M. E., Fillipetti, V. A., Manucci, V., \& Apaz, A. (2011). Programa de intervención, para fortalecer funciones cognitivas y lingüísticas, adaptado alcurrículo escolar em niños em riesgo por pobreza. Interdisciplinaria, 28(1), 17-36.

Griffith, E. M., Pennington, B. F., Wehner, E. A., \& Rogers, S. J. (1999). Executive functions in young children with autism. Child Development, 70, 817-832.

Houdé, O., Rossi, S., Lubin, A., \& Joliot, M. (2010). Mapping numerical processing, reading, and executive functions in the developing brain: An fMRI meta-analysis of 52 studies including 842 children. Developmental Science, 13(6), 876-885.

Hughes, C., \& Graham, A. (2008). Executive functions and development. In J. Reed, \& J. Warner-Rogers, (Eds.), Child neuropsychology: Concepts, theory, and practice (pp. 264-283). Chichester: Wiley-Blackwell.

Huizinga, M., Dolan, C. V., \& van der Molen, M. W. (2006). Agerelated change in executive function: Development trends and a latent variable analysis. Neuropsychologia, 44, 2017-2036.

Johnson, M.H. (2000). Functional brain development in infants: Elements of an interactive specialization framework. Child Development, 71(1), 75-81.

Johnson, M. H., Grossmann, T., \& Cohen Kadosh, K. (2009). Mapping functional brain development: Building a social brain through interactive specialization. Development Psychology, 45(1), 151-159. 
Johnstone, S. J., Barry, R. J., Markovska, V., Dimoska, A., \& Clarke, A. R. (2009). Response inhibition and interference control in children with AD/HD: A visual ERP investigation. International Journal of Psychophysiology, 72, 145-153.

Kerr, A., \& Zelazo, P. D. (2004). Development of "hot" executive function: The children's gambling task. Brain and Cognition, 55, 148-157.

Kesek, A., Cunningham, W. A., Packer, D. J., \& Zelazo, P. D. (2011). Indirect goal priming is more powerful than explicit instruction in children. Development Science, 14(5), 944-948.

Klenberg, L., Korkman, M., \& Lahti-Nuuttila, P. (2010). Differentia development of attention and executive functions in 3- to 12-yearold Finnish children. Developmental Neuropsychology, 20(1), $407-$ 428.

Kluwe-Schavion, B., Viola, T. W., \& Grassi-Oliveira, R. (2012) Modelos teóricos sobre constructo único ou múltiplos processos das funções executivas. Revista Neuropsicologia Latinoamericana, 4(2), 29-34.

Lamm, C., Zelazo, P. D., \& Lewis, M. D. (2006). Neural correlates of cognitive control in childhood and adolescence: Disentangling the contributions of age in executive function. Neuropsychologia, 44, 2139-2148.

Laing, E., \& Hulme, C. (1999). Phonological and semantic processes influence beginning readers' ability to learn to read words. Journal of Experimental Child Psychology, 73, 183-207.

Levin, H. S., Song, J., Ewing-Cobbs, L., Chapman, S. B., \& Mendelsohn, D. (2001). Word fluency in relation to severity of closed head injury, associated frontal brain lesions, and age at injury in children. Neuropsychologia, 39, 122-131.

Liebermann, D., Giesbrecht, G. F., \& Müller, U. (2007). Cognitive and emotional aspects of self-regulation in preschoolers. Cognitive Development, 22, 511-529.

Lima, M., Prando, M. L., Renner, A. M., De Nardi, T., Fonseca, R. P., \& Grassi-Oliveira, R. (2011). Tarefa n-back visual: Construção de um instrumento de avaliação de memória de trabalho para crianças. Revista Psico, 42(4), 487-493.

Lipina, S. J., Martelli, M. I., Vuelta, B. L., Injoque-Ricle, I., \& Colombo, J. A. (2004). Pobreza y desempenho ejecutivo em alumnos preescolares de la ciudad de Buenos Aires (Republica Argentina). Interdisciplinaria, 21(2), 153-193.

Marcovitch, S., \& Zelazo, P. D. (2009). A hierarchical competing systems model of the emergence and early development of executive function. Development Science, 12(1), 1-18.

Martin-González, R., Gonzalez-Pérez, P. A., Izquierdo-Hernandez, M., Hernández-Exposito, S., Alonso-Rodriguez, M. A., QuinteroFuentes, I., \& Rubio-Morell, B. (2008). Neuropsychological assessment of memory in attention deficit hyperactivity disorder: The role of executive functions. Revista de Neurología, 47(5), 225-230.

Matute, E., Chamorro, Y., Inozemtseva, O., Barrios, O., Rosselli, M., $\&$ Ardila, A. (2008). Efecto de la edad en una tarea de planificacíon y organizacíon ('pirâmide de México') en escolares: The effect of age in a planning and arranging task ("Mexican pyramid") among school children. Revista de Neurología, 47(2), 61-70.

McAuley, T., \& White, D. A. (2010). A latent variables examination of processing speed, response inhibition, and working memory during typical development. Journal of Experimental Child Psychology, 108(3), 453-468

Miranda, M. C., \& Muszkat, M. (2004). Neuropsicologia do desenvolvimento. In V. M. Andrade, F. H. dos Santos, \& O. F. A. Bueno (Eds.), Neuropsicologia hoje. São Paulo: Artes Médicas.

Müller, U., Dick, A. S., Gela, K., Overton, W. F., \& Zelazo, P. D. (2006). The role of negative priming in preschoolers' flexible rule use on the dimensional change card sort task. Child Development, $77(2), 395-412$.
Muscara, F., Catroppa, C., \& Anderson, V. (2008). The impact of injury severity on executive function 7-10 years following pediatric traumatic brain injury. Developmental Neuropsychology, 33(5), 623-636.

Nieto, A., Galtier, I., Barroso, J., \& Espinosa, G. (2008). Verbal fluency in school-aged Spanish children: Normative data and analysis of clustering and switching strategies. Revista de Neurología, 46(1), $1-15$.

Pureza, J., Jacobsen, G., Oliveira, R. G., \& Fonseca, R. P. (2011). Relationships between executive functions tasks in late childhood. Psychology \& Neuroscience, 4(3), 369-376.

Raven, J. C., Court, J. H., \& Raven, J. (1995). Manual for Raven's Progressive Matricesand Vocabulary Scales: Section 2. Coloured progressive matrices. Oxford: Oxford Psychologists Press.

Raven, J. C., Court, J. H., \& Raven, J. (1998). Manual for Raven's Progressive Matrices and Vocabulary Scales: General overview. Oxford: Oxford Psychologists Press.

Russo, N., Flanagan, T., Iarocci, G., Berringer, D., Zelazo, P.D., \& Burack, J. A. (2007). Deconstructing executive deficits among persons with autism: implications for cognitive neuroscience. Brain and Cognition, 65, 77-86.

Salles, J. F., Fonseca, R. P., Cruz-Rodrigues, C., Mello, C., Barbosa T., \& Miranda, M. C. (2011). Desenvolvimento do Instrumento de Avaliação Neuropsicológica Breve Infantil NEUPSILIN-INF. Psico USF, 16(3), 297-305.

Siqueira, L. S., Scherer, L. C., Rappold, C. T., \& Fonseca, R. P. (2010). Hayling Test-Adult Version: Applicability in the assessment of executive functions in children. Psychology \& Neuroscience, 3(2), 189-194.

Soltész, F., Goswami, U., White, S., \& Szücs, D. (2010). Executive function effects on numerical development in children: Behavioural and ERP evidence from a numerical Stroop paradigm. Learning and Individual Differences, 21(6), 662-671.

Tamnes, C. K., Ostbya, Y., Walhovda, K. B., Westlyea, L. T., Due-Tønnessenb, P., \& Fjell, A. M. (2010). Neuroanatomical correlates of executive functions in children and adolescents: A magnetic resonance imaging (MRI) study of cortical thickness. Neuropsychologia, 48, 2496-2508.

Thibaut, J. P., French, R., \& Vezneva, M. (2010). Cognitive load and semantic analogies: Searching the semantic space. Psychonomic Bulletin, \& Review, 17(4), 569-574.

Towse, J. N., \& McLachlan, A. (1999). An exploration of random generation among children. British Journal of Developmental Psychology, 17, 363-380.

Towse, J. N., \& Neil, D. (1998). Analyzing human random generation behavior: A review of methods used and a computer program for describing performance. Behavior Research Methods, Instruments, \& Computers, 30(4), 583-591.

Vannier, A. L., Chevignard, M., Pradat-Diehl, P., Abada, G., \& De Agostini, M. (2006). Assessment of unilateral spatial neglect in children using the Teddy Bear Cancellation Test. Developmental Medicine \& Child Neurology, 48,120-125.

Völkl-Kernstock, S., Bauch-Prater, S., Ponocny-Seliger, E., \& Feucht, M. (2009). Speech and school performance in children with benign partial epilepsy with centro-temporal spikes (BCECTS). Seizure, $18(5), 320-326$.

Vuontonela, V., Steenari, M., Carlson, S., Koivisto, J., Fjallberg, M., \&Aronen, E. T. (2003). Audiospatial and visuospatial working memory in 6-13 year old school children. Learning \& Memory, 10, 74-81.

Willcutt, E. G., Doyle, A. E., Nigg, J. T., Faraone, S. V., \& Pennington, B. F. (2005). Validity of executive function theory of attentiondeficit/hyperactivity disorder: a meta-analytic review. Biological Psychiatry, 57, 1336-1346. 